partner notification interventions in UK general practises (primary care clinics). Practices were paid for recruitment which was managed by clinic staff. Despite training, there were barriers to testing and recruitment: staff experienced competing priorities, were reluctant to mention testing, perceived that STIs were uncommon in their population, and believed that few young people attended the clinic. We aimed to assess the effect of intensive researcher led recruitment on testing rates and compare with prior optimised recruitment by clinic staff.

Methods Ten general practises in North and South East England agreed to participate. We trained research staff on recruitment processes and allocated a researcher to each general practise. The researcher approached potentially eligible young people in the waiting room for a three week period and offered Chlamydia testing and trial enrolment. We compared testing and recruitment rates with those achieved by clinic staff over a period of 3 months.

Results $114516-25$ year olds were approached in the 10 practises during intensive recruitment periods, of whom $43 \%$ consented and tested. Of refusals, $37 \%$ had tested elsewhere. Most practises achieved $45-50$ tests per 3 week period, compared with 3-4 per month during 3 months of optimised clinic staff recruitment.

Conclusion External researcher led intensive recruitment increased testing levels substantially and should be considered as an alternative to clinic staff enrolment in primary care. Even if enrolment targets are met, the impact of sexual health interventions in primary care will be limited unless barriers to engagement in sexual health are overcome.

\section{P3.386 PREVENTION WITH POSITIVES IN NIGERIA: WHAT HAVE WE LEARNT}

doi:10.1136/sextrans-2013-051184.0839

O D Obi Peter, C I T Chinomnso. Traffina Foundation for Community Health, Asokoro, Nigeria

Background The introduction of care and treatment at the service delivery points at the community and the clinical settings- hospital facilities for prevention with positives have giving the HIV/AIDS, STIs, TB management high quality significant improvement in the first eight months of implementation in Nigeria.

Methods Association of Positive youth in Nigeria is a national non governmental organisation in Nigeria, involved in HIV prevention, care and support. APYIN started implementing HIV prevention strategies in 2009 with a focus on involving HIV- positive people in prevention. The strategies included: counselling on prevention of HIV to positive persons this involved discussion of behavioural intervention in medical and counselling visits. Promoting the use and provision of condoms to sexually active HIV-positive individuals, promoting adherence to antiretroviral drugs by counselling, use of pills boxes and medicine companions.

Encouraging HIV-positive persons to disclose HIV status to sex partners either by self or counsellor mediated during targeting partners and children born to all people living with HIV/AIDS.

Results Most of the persons living HIV realise that they have a role to play in prevention of HIV. There is $8.5 \%$ increase in the uptake of condoms by HIV-positive persons between the year 2008 and 2009. Antiretroviral therapy adherence levels of $92 \%$ of the clients on ART with adherence $>95 \%$. In the same period there is an increase of $50 \%$ of HIV- positive individuals disclosing HIV status to partners. Community awareness of HIV has increased in the area serviced by the organisation.

Conclusion Increase collaboration between the clinical and community base interventions; regular monitoring of the community response for improvement. The capacity building of community staff. HIV positive persons are very important partners in HIV prevention. Therefore their involvement should be prioritised.

\section{P3.387 PREVALENCE AND PREDICTORS OF RAPE PERPETRATION AMONG MALE SECONDARY SCHOOL STUDENTS IN PERI- URBAN XHOSA COMMUNITIES IN SOUTH AFRICA}

\author{
doi:10.1136/sextrans-2013-051184.0840
}

1.2Z A Kaufman, ' $1 \mathrm{E}$ B Kaufman, ' $\mathrm{S}$ Dringus, 'H A Weiss, ${ }^{2} \mathrm{~S}$ Delany-Moretlwe, 'D A Ross. 'London School of Hygiene and Tropical Medicine, London, UK; 'Wits Reproductive Health and HIV Institute, Johannesburg, South Africa

Background A 2009 survey of adult men in South Africa found that $27.6 \%$ reported ever having perpetrated rape. The majority reported first perpetrating rape before age 20. Intimate-partner violence and rape are associated with HIV. We assessed the prevalence and predictors of reported rape perpetration among in-school, adolescent males at baseline of a cluster-randomised trial.

Methods Grade-nine males at 46 secondary schools in Cape Town and Port Elizabeth townships completed a confidential, selfadministered questionnaire on touchscreen mobile phones. The questionnaire assessed structural/demographic, psychosocial, lifestyle, and behavioural/relationship factors, and reported rape perpetration. Multiple logistic regression models were used to identify factors associated with reported rape perpetration, adjusting for school-level clustering and more distal variables in the conceptual framework.

Results A total of 1991 boys were enrolled (median age 16 years, $95.6 \%$ Xhosa-speaking). Of these, 342 (17.2\%) reported ever having perpetrated rape. Factors associated with reported rape perpetration were older age $(\mathrm{AOR}=1.14,95 \% \mathrm{CI}=1.01-1.29)$, having a father with no secondary education $(\mathrm{AOR}=1.42,95 \% \mathrm{CI}=1.01-1.99)$, living with one's father ( $\mathrm{AOR}=1.37,95 \% \mathrm{CI}=1.01-1.86)$, having been traditionally circumcised ( $\mathrm{AOR}=2.22,95 \% \mathrm{CI}=1.21-4.09$ ), maledominant gender norms ( $\mathrm{OR}=1.33,95 \% \mathrm{CI}=1.05-1.68)$, harmful alcohol use ( $\mathrm{AOR}=2.02,95 \% \mathrm{CI}=1.41-2.90)$, having had sex while drunk in the last year $(\mathrm{OR}=1.86,95 \% \mathrm{CI}=1.26-2.76)$, and having ever perpetrated physical violence against a partner $(\mathrm{OR}=2.80,95 \%$ $\mathrm{CI}=1.93-4.07)$. Rape perpetration was also associated with low self-efficacy to prevent HIV ( $\mathrm{OR}=2.52,95 \% \mathrm{CI}=1.77-3.57)$, more stigmatising attitudes towards people living with $\mathrm{HIV}(\mathrm{AOR}=1.44$, $95 \% \mathrm{CI}=1.17-1.78)$, having had partner $5+$ years younger in the last year $(\mathrm{OR}=2.10,95 \% \mathrm{CI}=1.24-3.55)$, self-reporting having been tricked or raped during one's first sex $(\mathrm{AOR}=1.91,95 \% \mathrm{CI}=1.10$ 3.32 ), and depressive symptoms (OR $=2.91,95 \% \mathrm{CI}=2.09-4.05)$,

Conclusion Rape perpetration is prevalent among school-going adolescent males. Development and evaluation of interventions addressing stereotypical/traditional masculine norms and behaviours and relevant structural/psychosocial factors is paramount in reducing rape perpetration. Further research should investigate the potential association between traditional Xhosa circumcision and rape perpetration.

\section{P3.388 SEXUAL VIOLENCE AND HIV/STIS IN GIRLS AND YOUNG WOMEN: TRENDS AND ASSOCIATION IN SOUTH WESTERN, NIGERIA}

doi:10.1136/sextrans-2013-051184.0841

N N M Otuonye, I R Onwuatuelo, C K Onwuamah, J 0 Okwuzu, A K Adeneye, C T Oparaugo, A A Adesesan. Nigerian Institute of Medical Research, Yaba, Lagos, Nigeria

Sexual violence put girls and young women at risk of long- lasting consequences in their reproductive health. The study focused on the trend of sexual violence and its' association with STIs/HIV amongst girls and young women in Western, Nigeria.

Data was obtained from in and out school girls and young women aged one to twenty eight years, using a cross sectional study design. Four hundred respondents were randomly selected and individually interviewed using a structured administered questionnaire which examined demographics, types of sexual violence, cases 